IFN Working Paper No. 727, 2008

\title{
Net Neutrality on the Internet: A Two-sided Market Analysis
}

Nicholas Economides and Joacim Tåg 


\title{
Network Neutrality on the Internet: A Two-sided Market Analysis*
}

\author{
Nicholas Economides ${ }^{\dagger}$ and Joacim Tåg
}

December 12, 2011

\begin{abstract}
We discuss network neutrality regulation of the Internet in the context of a two-sided market model. Platforms sell broadband Internet access services to residential consumers and may set fees to content and application providers on the Internet. When access is monopolized, cross-group externalities (network effects) can give a rationale for network neutrality regulation (requiring zero fees to content providers): there exist parameter ranges for which network neutrality regulation increases the total surplus compared to the fully private optimum at which the monopoly platform imposes positive fees on content providers. However, for other parameter values, network neutrality regulation can decrease total surplus. Extending the model to a duopoly of residential broadband ISPs, we again find parameter values such that network neutrality regulation increases total surplus suggesting that network neutrality regulation could be warranted even when some competition is present.
\end{abstract}

Keywords: Network neutrality, two-sided markets, Internet, monopoly, duopoly, regulation, discrimination, AT\&T, Verizon, Comcast, Google.

JEL classification: L1, D4, L12, L13, C63, D42, D43.

\footnotetext{
*Economides acknowledges generous support from the Newhouse Foundation and the Entertainment, Media and Technology program of the Stern School of Business. Tåg wishes to thank the ASLA-Fulbright Program in Finland, the Commerce and Industry Fund at Hanken and the Marcus Wallenberg Foundation for financial support. He wrote part of the paper within the Gustaf Douglas Research Program on Entrepreneurship at the Research Institute of Industrial Economics and he acknowledges financial support from the Marianne and Marcus Wallenberg Foundation and the Jan Wallander and Tom Hedelius Foundation. We thank Jay Pil Choi, Chris Dellarocas, Andrei Hagiu, Tore Nilssen, Lars Sørgard and participants at seminars at the Smith School of Business of University of Maryland, Helsinki Center for Economic Research (HECER), Research Institute of Industrial Economics, the AEA Meetings 2011, the Telecommunications Policy Research Conference, the editor and two anonymous referees for their comments and suggestions.

$\dagger$ Stern School of Business. New York University, 44 West Fourth Street, NY 10012-1126, New York, U.S.A. Phone: +1 (212) 998-0864. E-mail: economides@stern.nyu.edu

† Corresponding author. Research Institute of Industrial Economics (IFN). P.O. Box 55665, SE-102 15 Stockholm, Sweden. Phone: +46 (0)8 665 4524. E-mail: joacim.tag@ifn.se
} 


\section{Introduction}

The Internet is the primary global network for digital communications. A number of different services are provided on the Internet, including e-mail, browsing, peer-to-peer services, Internet telephony (Voice over Internet Protocol "VOIP"), and many others. A number of different functions/applications run on top of the Internet browser, including information services, display of images, transmission of video and other features.

Since the inception of the Internet, information packets are transported on the Internet under "network neutrality." This is a regime that does not distinguish in terms of price between bits or packets depending on the services for which these bits and packets are used or on the identities of the uploader and downloader. The typical contract of an Internet service provider (ISP) with a customer gives the customer access to the whole Internet through a physical or virtual pipe of a certain bandwidth. Similarly, an ISP buys from an Internet backbone network access to the whole Internet through a physical or virtual pipe of a certain bandwidth in a service called "transit." "Transit" delivers access to the buyer to the whole Internet and therefore the buyer/ISP does not need to have any contractual relationship with any other ISP except its backbone provider. ${ }^{1}$

The price a customer pays to an ISP for Internet access depends crucially on the availability of competing ISPs for this customer. Customers that are not locationally constrained and can connect to the Internet at many locations can negotiate very small connection charges. Content/applications providers are typically not locationally constrained and have negotiated very small Internet access charges. In contrast, residential customers typically face a local monopoly or duopoly and have much higher charges.

As search services, video services and digital distribution of content over the Internet are growing, Internet broadband access providers AT\&T, Verizon and a number of cable TV companies have recently demanded additional compensation for carrying valuable digital services. Ed Whitacre, AT\&T's then CEO, was quoted in BusinessWeek referring to AT\&T's Internet infrastructure: "Now what they would like to do is use my pipes free, but I ain't going to let them do that because we have spent this capital and we have to have a return on it." ${ }^{2}$ However, no one is using the Internet for free. In a transmission of an information packet the ISPs on

\footnotetext{
${ }^{1}$ ISPs can also accept payment in kind, that is, barter, called 'peering.' Peering is a restricted service whereby two interconnecting networks agree not pay each other for carrying the traffic exchanged between them as long as the traffic originates and terminates in the two networks. For a more detailed description, see Economides (2005, 2007).

${ }^{2}$ Interview with Ed Whitacre, BusinessWeek November 7, 2005. Q: How concerned are you about Internet upstarts like Google (GOOG), MSN, Vonage, and others? A: How do you think they're going to get to customers? Through a broadband pipe. Cable companies have them. We have them. Now what they would like to do is use my pipes free, but I ain't going to let them do that because we have spent this capital and we have to have a return on it. So there's going to have to be some mechanism for these people who use these pipes to pay for the portion they're using. Why should they be allowed to use my pipes? The Internet can't be free in that sense, because we and the cable companies have made an investment and for a Google or Yahoo! (YHOO) or Vonage or anybody to expect to use these pipes [for] free is nuts!
} 
both sides pay the Internet backbone and each ISP is paid by its customer. ${ }^{3}$ AT\&T, together with Verizon and cable TV companies, are asking for the abolition of "network neutrality."

In terms of pricing, this would imply that content and application providers (such as Google, Yahoo, MSN, or Disney) would be forced to pay the a residential consumers' Internet service provider to ensure that the consumer can access their services. The Internet service providers have also expressed a desire to be able to apply different prices to different content providers, even for the same type of information transmitted to consumers. This would imply that a residential ISP could potentially charge Google more for making the Google search service available to consumers than what it charges Microsoft for making its search service available.

In abolishing network neutrality, telephone and cable companies are departing from the "end-to-end principle" that has governed the Internet since its inception. ${ }^{4}$ Under the end-to-end principle, computers attached to the Internet that are sending and receiving information packets did not need to know the structure of the network and could just interact end-to-end. Thus, there could be innovation "at the edge" of the network without interference from network operators. ${ }^{5}$ The way the Internet has operated so far is a radical departure from the operating principles of the traditional digital electronic networks predating it, such as Compuserve, Prodigy, AOL, AT\&T Mail, MCI Mail and others. These older electronic networks were centralized with very little functionality allowed at the edge of the network.

From an economics point of view, the departure from network neutrality regulation will have two primary consequences.

- It will introduce the potential of two-sided pricing on the Internet where a transmission company controlling some part of the Internet (here last mile access) will charge a fee to content or application firms "on the other side" of the network which typically did not have a contractual relationship with it. This payment by a content or applications provider would be over and above the traditional one-sided payment to its ISP for providing access and transmission of information packets.

- It will introduce the possibility for prioritization, which may enhance the arrival time of information packets originating from paying content and application firms "on the other side," and may degrade the arrival time of information packets that originate from nonpaying firms. This has the possibility of increasing efficiency of packet transfers over the Internet, such that more time-sensitive packets are given prioritized access. But it can also effectively exclude access to non-paying firms' content and applications.

In this paper, we deal with the issue of introducing two-sided market pricing by formally building a model of a two-sided market. We thus only concentrate on the issue of one-sided versus two-sided pricing (which we think should play a larger role in the debate) and ignore other

\footnotetext{
${ }^{3}$ See Economides $(2005,2007)$.

${ }^{4}$ For more on the end-to-end argument, see e.g. Saltzer, Reed and Clark (1984).

${ }^{5}$ See Cerf $(2006 a, b)$ for a detailed explanation of this argument.
} 


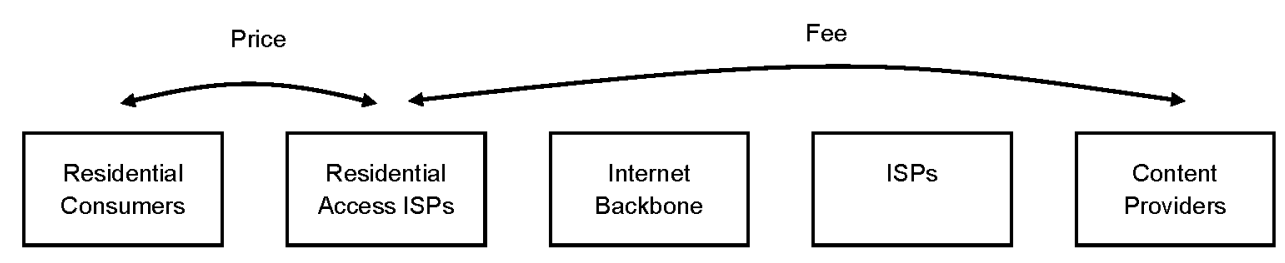

Figure 1: We take the Internet backbone and ISPs on the side of content providers as competitive and consider the price for Internet access that residential consumers pay and possible direct fees imposed on content providers by residential ISPs. The latter are possible if network neutrality is abolished and an ISP can determine the origins of packets it delivers to consumers.

(admittedly important) issues such as exclusion of content providers, dynamic investment incentives and price discrimination. In particular, we abstract entirely from prioritization issues in order to focus on two-sided pricing.

We explicitly model the Internet broadband market as a two-sided network consisting of broadband users on one side and content and applications providers on the other. Prices imposed on both sides have direct implications on the number of broadband consumers as well as on the number of active providers of content and applications. In our framework, network neutrality is defined as the restriction that Internet Service providers cannot directly charge content providers for access to consumers, i.e., the price on one side of the market is constrained to zero. We only consider direct charges to content providers over and above charges for sending and receiving traffic from the Internet backbone. Figure 1 shows the conceptual structure of the Internet connecting consumers and content providers. ${ }^{6}$

Our setup is based on the standard two-sided market model of Armstrong (2006). We discuss the desirability of departing from network neutrality to allow the residential ISP to initiate a positive fee to the content and applications side of the market, besides the price it charges to users/subscribers. Our main point is that cross-group externalities (network effects) between consumers and content providers can provide a rationale for network neutrality regulation: for some parameter values, preventing residential ISPs from charging content providers for making their services available to residential consumers increases the total social surplus. However, there also exist parameter values for which this result is overturned. Therefore, ultimately whether network neutrality regulation is desirable or not is ambiguous in a monopoly ISP setting. We then extend the model to a duopoly ISP setting with multi-homing content providers and single-homing consumers and show that imposing network neutrality weakly increases total surplus (given that the market on the consumer side is fully covered). We show that, when the market is fully covered (so everyone has Internet access), network neutrality will always increase total surplus if content providers value consumers more than consumers value content providers. The reason for the unambiguous increase is the surplus loss arising when some content providers exit when positive fees are imposed on them. If we additionally allow

\footnotetext{
${ }^{6}$ Of course, to be able to charge some providers and not others requires that the residential ISP inspects packets to determine whether they originate from a paying firm.
} 
for demand expansion effects on the consumer side, there are again parameter values for which network neutrality increases total surplus but in general network neutrality can both increase or decrease total surplus.

Despite a considerable literature discussing the rights and legal issues of network neutrality and its abolition, the literature on economic analysis of this issue is thin (Schuett (2010) provides a survey). In a paper relating to the establishment of multiple "lanes" or quality options for application providers, Hermalin and Katz (2007) analyze a model where network neutrality is equivalent to a single product quality requirement. ${ }^{7}$ Focusing on congestion, Cheng, Bandyopadhyay and Guo (2011) model two content providers who can avoid congestion by paying ISPs for preferential access. ${ }^{8}$ They find that abolishing network neutrality will benefit ISPs and hurt content providers. Choi and Kim (2010) study both a static and a dynamic setting focusing on how innovation incentives are affected by network neutrality. They find ambiguous results regarding the impact of network neutrality regulation on welfare, but highlight that, in a dynamic setting, network neutrality regulation affects the incentives of the network operator by either allowing the network operator to charge more/less for access or by allowing the network operator to sell rights to prioritized delivery of content. ${ }^{9}$ Economides and Hermalin (2010), despite assuming network congestion, find that network neutrality is welfare-superior to bandwidth subdivision and prioritization for a wide class of utility functions, and characterize exceptional cases where prioritization is desirable. They also find that the incentive to invest in bandwidth is greater when the ISPs can price discriminate, and investment in bandwidth may mitigate or even reverse the welfare losses of departures from network neutrality. A paper similar in spirit to Economides and Hermalin (2010) is Krämer and Wiewiorra (2010). It studies a two-sided monopoly market model focusing on congestion and prioritization of access with content providers vertically differentiated and homogeneous consumers. In that model, net-

\footnotetext{
${ }^{7}$ Hermalin and Katz (2007) do not address the issue of the reduction of the "standard" lane for Internet access that is likely to reduce consumers' welfare. They do consider a two-sided market model, but their model does not have positive cross group externalities.

${ }^{8}$ See also Jamison and Hauge (2008).

${ }^{9}$ In addition, Chen and Nalebuff (2007) analyze competition between complements and briefly touch upon the issue of network neutrality. Some services that are offered by an ISP may also be offered over the Internet (such as Vonage or Skype). There is a concern that the ISP would like to disrupt the quality of the services of its competitors to further its own product. However, the authors show that this would not be profit maximizing in their model since a monopolist ISP benefits from valuable complements such as VOIP services (a higher price for internet access could be charged instead of trying to force consumers to its own VOIP service). Hogendorn (2007) analyzes the differences between open access and network neutrality and emphasizes that these are different policies that may have different implications. Hogendorn interprets network neutrality in a slightly different way than most of the literature. Open access refers to allowing intermediaries access to conduits (so that intermediaries such as Yahoo can access conduits like AT\&T at a nondiscriminatory price), while network neutrality is interpreted to mean that content providers have unrestricted access to intermediaries (so that Yahoo cannot restrict which content providers can be reached through its portal). Under network neutrality, a smaller number of intermediaries enter the market due to decreased profits. Open access, on the other hand, increases the entry of intermediaries since they now have free access to conduits. In general, Hogendorn finds that open access is not a substitute for network neutrality regulation. Finally, Economides (2008) discusses several possible price discrimination strategies that may become available if network neutrality is abolished. He presents a brief model showing that the total surplus may be lower when the platform imposes a positive fee on an application developed for it because the fee raises the marginal cost of the application and hence also its price.
} 
work neutrality means that the ISP cannot build a "fast-lane" that would, at a price, provide prioritized access over best-effort delivery. Musacchio, Schwartz and Walrand (2009) study the interaction between many content providers and many ISPs connecting content providers to consumers. The content providers derive profits from advertising revenues arising from consumer clicks.

In contrast to the above literature, we focus purely on the issue of two-sided pricing made possible by the violation network neutrality and the interaction between the two sides generated by cross-group externalities heterogeneity among both consumers and content providers. Hence, our paper is related to the literature on two-sided markets (e.g. Armstrong (2006), Caillaud and Jullien (2003), Hagiu (2009), Rochet and Tirole (2003, 2006), Nocke, Peitz and Stahl (2007) and Weyl (2010)). In particular, we build on the approach in Armstrong (2006) by extending it to study network neutrality regulation, and by studying optimal regulation of one price in a two-sided market while the platforms are allowed to optimally set the other price in response. Related is also Hagiu (2007) who discusses open versus proprietary platforms, where open platforms imply zero prices on each side of the market. In contrast, we allow one price to be positive while the other is constrained to zero under network neutrality regulation. A central result in Hagiu (2007) is that a monopoly proprietary platform can sometimes be welfare superior to an open platform because pricing by the platform partially internalizes externalities across the two sides. In our setting, however, the result is that limiting the pricing behavior of proprietary platforms (the ISPs) can sometimes be welfare superior. Furthermore, in contrast to Hagiu (2007), we also study a duopoly setting and show that with a fully covered market, restricting pricing behavior of duopolist platforms is unambiguously welfare superior to allowing two-sided pricing.

We have structured our paper in the following way. We first present and evaluate the impact of network neutrality regulation in a monopoly model in section 2 . In section 3 , we extend the monopoly model to a duopoly setting with multi-homing content providers. Concluding remarks are given in section 4.

\section{Platform Monopoly}

We start with a platform monopoly model of a two-sided market. A platform (say, a telephone company such as AT\&T) sells broadband Internet access to residential consumers at a subscription price $p$ and possibly collects a fee $s$ from each content or application provider to allow the content to reach the consumer. We assume that the platform monopolist (and later in the paper, duopolists) only offers linear fee contracts, i.e., it does not offer quantity discounts and does not offer take-it-or-leave-it contracts with lump-sum fees. ${ }^{10}$ Furthermore, we abstract from the

\footnotetext{
${ }^{10}$ One could alternatively view our setup also as only considering consumer and content provider use of a high speed dedicated last mile access line offered to content providers requiring a high level of quality of service to ensure that, for example, HD video transmissions work well.
} 
full complexity of the Internet, which consists of many interconnected networks and assume that the networks that lie between the access provider and the content provider are passive (see Figure 1). ${ }^{11}$ Finally, we assume that the cost of providing the platform service is $c$ per consumer.

\subsection{Consumers}

Consumers are interested in accessing the Internet to reach search engines (e.g. Google), online stores (e.g. Amazon), online auctions (e.g. eBay) and online video, audio, still pictures, and other content. A consumer $i$ 's location (type) $x_{i}$ indexes his/her utility for accessing the Internet through the ISP and interacting with the content providers. Consumers pay a transportation cost equal to $t$ per unit of distance "traveled." Consumers' locations are uniformly distributed on the interval zero to one with the platform located at $x=0$. This specification allows for an easy extension to a duopoly setting. For our interpretation of consumer heterogeneity to be consistent with both the monopoly and duopoly models, one should view the monopoly model as a model of "horizontal differentiation with a missing ISP." Consumers with a high $x$ would have liked to purchase access from the missing ISP but, in its absence, stay out of the market. This modeling setup is a common way in the literature to model competition. It is also consistent with Armstrong (2006), who uses a similar setup to go from a monopoly to a duopoly model. A typical interpretation of heterogeneity is that consumers have preferences over two ISPs, say AT\&T and Comcast, as a result of branding and/or prior experience with the companies. This makes competition between the ISPs imperfect and it is this notion that our model is designed to capture. Moreover, there is empirical support for that consumer heterogeneity matters in the ISP market. Chen and Savage (2011) empirically estimate a model where DSL and Cable modem providers compete in duopoly and measure consumer heterogeneity as the standard deviation of the population's number of years of schooling. They find that consumer preference heterogeneity has a positive and significant effect on the price, consistent with a generalized Hotelling model.

Consumer $i$ 's utility is specified as

$$
u_{i}=v+b n_{c p}-t x_{i}-p
$$

where $v>c$ is an intrinsic value that a consumer receives from connecting to the Internet irrespective of the amount of content, $b$ is the marginal value that a consumer places on an additional content provider on the Internet and $n_{c p}$ is the number of active content providers. ${ }^{12}$

\footnotetext{
${ }^{11}$ If the in-between networks also attempted to charge a fee to content providers, there would be the possibility of high prices because of double or multiple marginalization.

${ }^{12}$ The benefit $v$ arises from Internet-enabled services that do not crucially depend on the number of other Internet subscribers or availability of content. An example is television services bundled with Internet access.
} 


\subsection{Content Providers}

Content providers rely on advertising revenue per consumer, $a$, to generate revenue. We assume content providers to be uniformly distributed on the unit interval and have a unit mass. We make the simplifying assumption that content providers are independent monopolists, each in its own market, and therefore do not compete with each other. Each content provider then earns $a n_{c}$, where $n_{c}$ is the number of consumers paying the platform for access to content providers. Thus, $a$ is the value for a content provider of an additional consumer connected to the Internet.

Content providers are heterogeneous in terms of the fixed costs of coming up with a business idea and setting up their business. A content provider indexed by $j$ faces a fixed cost of $f y_{j}$, where $y_{j}$ is the index of the content provider's location on the unit interval. ${ }^{13}$ The marginal costs for serving advertisements to consumers are taken to be zero. Each content provider may have to pay the platform a lump-sum fee equal to $s$ to gain access to users. This fee is assumed to be the same for all content providers and it is set by the platform. ${ }^{14}$ Thus, a content provider j's profit is

$$
\pi_{j}=a n_{c}-s-f y_{j}
$$

Network neutrality regulation corresponds to the case where $s$ is zero. As discussed earlier, the traditional fees paid for transit service by content/applications providers are small, and here we take them to be zero at the status quo network neutrality regime. ${ }^{15}$ Figure 2 shows the interaction between consumers and content providers through the platform.

\subsection{Demand}

In this two-sided market, the demand for content depends on the expected amount of content provided since more consumers will connect to the network if more expected content is available. In addition, the provision of content depends on the expected number of consumers. When the expected number of consumers is $n_{c}^{e}$ and the expected number of content providers is $n_{c p}^{e}$, the marginal consumer $x_{i}$ who is indifferent between subscribing to the Internet not subscribing is located at

$$
x_{i}=n_{c}=\frac{v+b n_{c p}^{e}-p}{t} .
$$

\footnotetext{
${ }^{13}$ We assume that the "market is not covered" in the sense that some content providers will always have such high fixed costs that they decide not to enter the market. Further, we assume demand for access to consumers to be differentiable.

${ }^{14}$ Alternatively, the fee to the platform can be specified to be proportional to the number of platform customers, and therefore a content provider's profits are: $\pi_{j}=(a-s) n_{c}-f y_{j}$ This results in a profit for the ISP of: $\Pi=$ $(p-c) n_{c}+s n_{c} n_{c p}$ While our demand functions in the monopoly case change for a general fee $s$ while being identical under net neutrality regulation with $s$ zero, our qualitative results in Proposition 1 are robust to this alternative specification.

${ }^{15}$ In any case, we can interpret the fee $s$ as the increment above the traditional transit fee charged for transporting the bits. Additionally, the consumers' ISP is usually not the same as the content providers' ISP.
} 


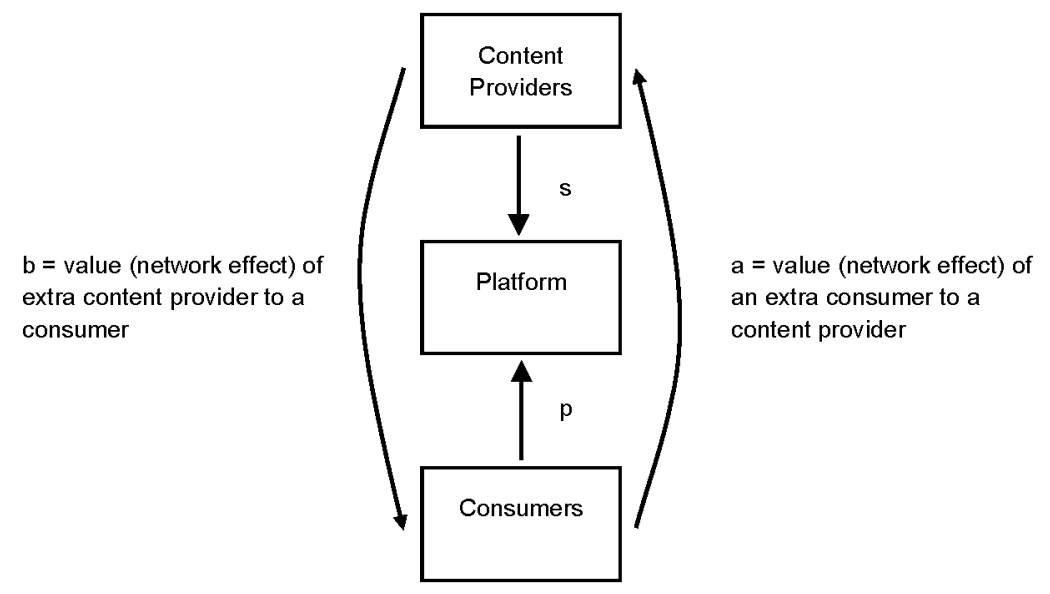

Figure 2: Interaction of consumers with content providers and vice versa through the platform.

The marginal content provider $y_{j}$ indifferent between being active and exiting the market is located at

$$
y_{j}=n_{c p}=\frac{a n_{c}^{e}-s}{f} .
$$

We look for fulfilled expectations equilibria where each side's expectations are fulfilled: $n_{c}^{e}=n_{c}$ and $n_{c}^{e}=n_{c p}$. The number of consumers and active content providers is then given by the solution to the simultaneous equation system (3) and (4), which is

$$
n_{c}(p, s)=\frac{f(v-p)-b s}{f t-a b}
$$

and

$$
n_{c p}(p, s)=\frac{a(v-p)-t s}{f t-a b} .
$$

Positivity of the demands requires $f t>a b$, and $v$ to be sufficiently large: $v>p+b s / f$ and $v>p+t s / a$.

We now study the monopoly platform optimum, the optimum with network neutrality regulation and the social optimum. Later we consider the welfare implications of imposing network neutrality.

\subsection{Monopoly Platform Optimum}

Consider first the monopoly platform private optimum under which the platform is free to set both the subscription price $p$ and the fee $s$ to content providers. The platform faces the problem of choosing $p$ and $s$ to maximize

$$
\Pi(p, s)=(p-c) n_{c}(p, s)+s n_{c p}(p, s) .
$$


Because the two markets provide complementary products, the monopolist finds an inverse relationship between $p$ and $s$; that is, maximizing with respect to $p$ results in a smaller $p$ when $s$ is larger, and maximizing with respect to $s$ results in a smaller $s$ when $p$ is larger. Specifically, the optimal $p$ for the monopolist given $s$, defined by $\partial \Pi / \partial p=0$, is given by

$$
p(s)=\frac{f(v+c)-(a+b) s}{2 f},
$$

and the optimal $s$ for the monopolist given $p$, defined by $\partial \Pi / \partial s=0$, is

$$
s(p)=\frac{a v+b c-(a+b) p}{2 t} .
$$

To ensure that the second order conditions are fulfilled here and in the analysis that follows, we assume that there is sufficient differentiation among consumers and content providers, or equivalently, that the network effects are not too strong. We also assume that the market is never entirely covered on the consumer or the content provider side.

Assumption 1. (i) Cross-group externalities (network effects) are not too strong, or equivalently, consumers and content providers are sufficiently differentiated: $f t-(a+b)^{2}>0$. (ii) The market is never entirely covered on the consumer or the content provider side: ft$(a+b)^{2}>\max \{f(v-c),(a+b)(v-c)\}$.

We make the assumption strong enough to cover not only the monopolist's maximization problem but the social planner's as well. Hence, the conditions in Assumption 1 come from the second order conditions and equilibrium participation levels when determining socially optimal prices. The conditions for obtaining interior solutions for the privately optimal monopoly prices are weaker, but we impose this stricter assumption here because we want to compare the privately optimal price balance to the socially optimal price balance under the same assumptions. ${ }^{16}$

Solving the two above equations simultaneously gives the consumers' subscription price and the fee charged to the content providers that maximize the platform's profits. ${ }^{17}$

$$
p^{M}=\frac{(2 f t-a b)(v+c)-b^{2} c-a^{2} v}{4 f t-(a+b)^{2}}
$$

and

$$
s^{M}=\frac{(a-b) f(v-c)}{4 f t-(a+b)^{2}} .
$$

\footnotetext{
${ }^{16} \mathrm{We}$ also focus only on interior solutions.

${ }^{17}$ The second order conditions for the monopolist's maximization problem are $-2 f /(f t-a b)<0,-2 t /(f t-$ $a b)<0$, and $4 f t-(a+b)^{2} /(f t-a b)^{2}>0$. These are satisfied under Assumption 1 (i). For $n_{c}^{M}$ and $n_{c p}^{M}$ to be less than 1 , it must be that $4 f t-(a+b)^{2}>2 f(v-c)$ and that $4 f t-(a+b)^{2}>(a+b)(v-c)$
} 
The participation levels are

$$
n_{c}^{M}=\frac{2 f(v-c)}{4 f t-(a+b)^{2}}
$$

and

$$
n_{c p}^{M}=\frac{(a+b)(v-c)}{4 f t-(a+b)^{2}} .
$$

and the profits of the monopoly platform are $\Pi^{M}=f(v-c)^{2} /\left(4 f t-(a+b)^{2}\right)$.

Superscript $M$ indicates the fully private optimum where both $p$ and $s$ are chosen by the monopoly platform. The price consumers pay is above the marginal cost if $2 f t-a(a+b)>0$, which holds under Assumption $1{ }^{18}$ The monopoly platform service provider sets a positive fee to content providers for accessing users $\left(s^{M}>0\right)$ only if $a / b>1$. This means that if content providers value additional consumers more highly than consumers value additional content providers, the platform will charge content providers a positive price for accessing consumers.

\subsection{Monopoly Platform Pricing under Network Neutrality Regulation}

Now consider the optimal choices of the monopoly platform provider under network neutrality regulation, that is, when, by regulation, $s=0$. The objective of the platform is now to maximize

$$
\Pi^{N N}=(p-c) n_{c}
$$

This gives the equilibrium price $p^{N N}=(v+c) / 2$. Equilibrium participation levels are $n_{c}^{N N}=$ $f(v-c) /(2(f t-a b))$ and $n_{c p}^{N N}=a(v-c) / 2(f t-a b)$. The platform's profits are $\Pi^{N N}=f(v-$ $c)^{2} /(4 f t-4 a b) \cdot{ }^{19}$

\subsection{Social Optimum with a Monopoly Platform}

We now solve for prices $p$ and $s$ that maximize the total surplus defined as $T S(p, s)=\Pi(p, s)+$ $C S_{c}(p, s)+\Pi_{c p}(p, s)$, where $\Pi(p, s)$ are platform profits,

$$
C S_{c}(p, s)=\int_{0}^{n_{c}(p, s)}\left(v+b n_{c p}(p, s)-t x-p\right) d x
$$

is consumer surplus, and

$$
\Pi_{c p}=\int_{0}^{n_{c p}(p, s)}\left(a n_{c}(p, s)-f y-s\right) d y,
$$

\footnotetext{
${ }^{18}$ More generally, although a below-cost price might not be implementable, the platform may tie other products with the offer for Internet access and thereby, in effect, obtain a negative price (Amelio and Jullien (2007)).

${ }^{19}$ The second order condition is $-2 f /(f t-a b)<0$, which is satisfied under Assumption 1 (i). For $n_{c}^{N N}$ and $n_{c p}^{N N}$ to be less than 1 , it must be that $2(f t-a b)>2 f(v-c)$ and that $2(f t-a b)>a(v-c)$
} 
is the total content providers' profits. Maximizing the total surplus, a planner chooses

$$
p^{*}=\frac{f t c-b(a+b) c-a(a+b) v}{f t-(a+b)^{2}}<c
$$

and

$$
s^{*}=-\frac{b f(v-c)}{f t-(a+b)^{2}}<0
$$

This results in maximized total surplus $T S\left(p^{*}, s^{*}\right)=f(v-c)^{2} / 2\left(f t-(a+b)^{2}\right) \cdot{ }^{20}$ The central idea here is that due to cross-group externalities, the network effects arising from the complementarity of the content and Internet subscription market imply that the planner sets a negative fee to content providers $s^{*}<0$ and a subscription price below its marginal cost $p^{*}<c$ to internalize the externality of content on subscribers and the externality of subscribers on content.

Note that if $a / b>1$ we have that $s^{*}<0<s^{M}$, i.e., that the unregulated monopolist sets a positive fee whereas the social optimal fee would be negative. More generally, if we put no restriction on $a / b$, the unregulated monopolist will impose a higher fee on the other side of the market than the regulated monopolist, $s^{*}<s^{M}$, when $f t>a(a+b)^{2} /(a+3 b)$, that is, when there is a sufficiently high differentiation among consumers and content providers.

\subsection{Welfare Implications of Imposing Network Neutrality}

In this subsection, we examine the welfare implications of imposing network neutrality by examining the changes in welfare that occur when moving from a privately optimal $p$, given $s=0$, to the full private optimum $\left(p^{M}\right.$ and $\left.s^{M}\right)$. We will show that there exist parameter values such that total surplus is higher under network neutrality regulation than under an unconstrained private optimum.

We can explicitly compare prices, equilibrium participation levels and surplus distribution across a setting where the platform is free to set both $s$ and $p$, and a setting of network neutrality regulation where $s$ is constrained to equal zero. We obtain the following proposition:

Proposition 1. Comparing network neutrality with the choice of the monopolist platform, we find that for $a / b>1$ : (i) total surplus is higher in network neutrality for sufficiently large differentiation parameters $f t$ and if $a / b<5$, and therefore there exist parameters such that network neutrality regulation increases total surplus; (ii) the content sector has higher profits and more content providers are active in network neutrality; and (iii) the platform and the consumers are better off without net neutrality.

\section{Proof. See Appendix A.1.}

\footnotetext{
${ }^{20}$ The second order conditions for the planner's maximization problem are $-f\left(f t-a^{2}-2 a b\right) /(f t-a b)^{2}<0$, $-t\left(f t-b^{2}-2 a b\right) /(f t-a b)^{2}<0$, and $\left(f t-(a+b)^{2}\right) /(f t-a b)^{2}>0$. These are satisfied under Assumption 1 (i): $f t-(a+b)^{2}>0$. For $n_{c}^{*}$ and $n_{c p}^{*}$ to be less than 1, it must be that $f t-(a+b)^{2}>f(v-c)$ and that $f t-(a+b)^{2}>(a+b)(v-c)$.
} 
Part (i) of Proposition 1 offers our main insight. Cross-group externalities and two-sided pricing could be a rationale for intervening and imposing network neutrality regulations that restrict two-sided pricing such that the price to content providers is zero. The reason is that the private platform does not fully internalize the cross-group externalities, and thus a restriction of zero price on one side of the market could increase total surplus by bringing the price balance closer to the socially optimal one. Parts (ii) and (iii) of Proposition 1 are also interesting in that the consumer surplus is higher in monopoly while total surplus can be higher at network neutrality. The intuition is that in monopoly, consumers benefit from a lower subscription price since the monopolist has incentives to attract more consumers to generate extra revenue from charging content providers. Although charging content providers leads to lower content provision, the direct effect of a lower subscription price dominates. In contrast, total surplus takes into account the profits of content providers, which are higher under network neutrality. Thus, despite consumers' surplus and platform profits being lower at network neutrality, the total surplus is higher for this parameter range.

The relative size of the cross group externalities, $a / b$, is important for this result since it determines the price balance in the market. A higher ratio implies that a content provider values an additional consumer more than a consumer values an additional content provider, implying that the monopolist platform charges content providers more. Outcomes where the removal of network neutrality leads to positive prices for content providers require this ratio to be high enough $(a / b>1)$. On the other hand, if it is too large, $(a / b>5)$, then the crossgroup externalities implies a strongly asymmetric price balance for both the social optimum and the private optimum. Imposing a zero price on one side then leads to the price balance deviating "too much" from the social optimum implying that total surplus decreases when imposing network neutrality. Finally, note that for smaller $f t$, the total surplus may decrease under network neutrality, as the increase in content provider profits is not sufficiently large to compensate for reductions in consumer surplus and platform profits.

\subsection{Second Best Solutions Under Regulation}

In a sense, imposing network neutrality is a shortcut for optimal regulatory intervention. As we have shown in section 2.6, a regulator who is able to choose both prices $p$ and $s$ will choose both prices below cost, leading to losses for the ISP. Besides the problem that the ISP does not break even, the regulator may not be able to set both prices, and in fact the FCC has committed not to regulate the user price $p$. So, in this section we consider two second best regulatory problems. First, we analyze the problem of optimal regulation of $s$, under the assumption that, given $s$, the ISP will be fully unconstrained in choosing price $p$. We find that then the regulator chooses a fee below cost, but revenues from the end user side are sufficient to give the ISP positive profits. Second, we analyze the problem of the regulator choosing both $p$ and $s$ under a minimum profit constraint. We show that for a wide range of profit minimums, the regulator 
would impose a negative fee $s$.

Proposition 2. Under Assumption 1 the following holds: (i) for $a / b \in(1,3)$ and ft sufficiently large, a total surplus maximizing planner/regulator, facing a platform monopolist that chooses the subscription price, will choose a below-cost fee to content providers, i.e., will subsidize content providers. Even paying the below-cost fee, the platform makes positive profits; (ii) for $a / b>1$, and $f t>a^{3} / b$, if the total surplus maximizing regulator is free to set both the price $p$

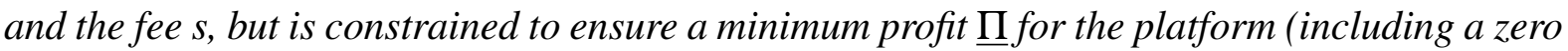
minimum profit), the total surplus maximizing regulator will set a negative fee if the minimum profit level is not too high $(\underline{\Pi}<\underline{\hat{\Pi}}$, where $\underline{\hat{\Pi}}$ is defined in Appendix B).

Proof. See below and Appendix B.

To see the first part of the proposition, note first that when the regulator chooses s expecting the profit maximizing best response of the ISP, $p(s)$, the regulator maximizes the constrained total surplus function $T S(p(s), s)$ with respect to $\mathrm{s}$. The solution is

$$
s^{* *}=\frac{f(v-c)\left(a\left(a^{2}-a b+2 b^{2}\right)+(a-3 b) f t\right)}{\left(a^{2}-6 a b-3 b^{2}\right) f t+4 f^{2} t^{2}-a(a-2 b)(a+b)^{2}}
$$

and the corresponding monopolist's user price is

$$
p^{* *}=\frac{a^{2}\left(c f t+b^{2}(2 c+v)\right)+a\left(2 b f t(2 c+v)-2 c b^{3}\right)-a^{4} v-f t\left(3 b^{2} c-2 f t(c+v)\right)}{\left(a^{2}-6 a b-3 b^{2}\right) f t+4 f^{2} t^{2}-a(a-2 b)(a+b)^{2}} .
$$

The fee $s^{* *}$ to content providers is negative provided that $a / b<3$ and $f t$ is sufficiently large. ${ }^{21}$ Given that the $s^{* *}$ is negative, the platform profits from consumers more than cover the subsidy to content providers if

$$
(f t)^{2}\left(3 a^{2}-10 a b-9 b^{2}+4 f t\right)-a(a+b)\left(a(a+b)\left(a^{2}-3 a b+4 b^{2}\right)+(a-3 b)(a+4 b) f t\right)>0,
$$

which is true for a sufficiently large $f t .^{22}$ Thus, the platform's profits are positive even when, following the regulator's orders, the platform imposes the negative fee $s^{* *}$ to the other side of the market. ${ }^{23}$

\footnotetext{
${ }^{21}$ For $s^{* *}<0$, it is sufficient to have $a\left(a(a-b)+2 b^{2}\right)<f t(3 b-a)$ which is implied by $a<3 b$ and $f t$ sufficiently large.

${ }^{22}$ The condition can be reformulated as

$4(f t)^{3}+\left(3 a^{2}-10 a b-9 b^{2}\right)(f t)^{2}-a(a+b)(a-3 b)(a+4 b) f t-a(a+b) a(a+b)\left(a^{2}-3 a b+4 b^{2}\right)>0$ or $A(f t)^{3}+B(f t)^{2}-C(f t)-D>0$ with $\mathrm{A}=4>0$. Hence, the expression is positive for $\mathrm{ft}$ sufficiently large.

${ }^{23}$ We have also considered the possibility that the regulator can set the price to users but allows the platform to set a fee to content providers. In that case, the regulator maximizes $T S(\widehat{p}, s(\widehat{p}))$ by choosing $\widehat{p}$. This leads the regulator to choose a below-cost user price $\widehat{p}-c=-\frac{(a+b)\left(2 a^{2} b+2 b f t-a\left(b^{2}+3 f t\right)\right)(c-v)}{(2 a-b) b(a+b)^{2}+\left(-3 a^{2}-6 a b+b^{2}\right) f t+4 f^{2} t^{2}}<0$ and, in response, the platform chooses an above-cost content-provider fee $s(\widehat{p})=\frac{f\left(a^{2} b+b^{3}-2 a f t\right)(c-v)}{(2 a-b) b(a+b)^{2}+\left(-3 a^{2}-6 a b+b^{2}\right) f t+4 f^{2} t^{2}}>0$.
} 
Next, consider the problem when the regulator can choose both prices $\mathrm{p}$ and $\mathrm{s}$ under a minimum profit constraint solving

$$
T S(p, s) \text { s.t. } \Pi(p, s)=\underline{\Pi}
$$

We prove Proposition 2(ii) in Appendix B. If the minimum profit to be achieved is below a specific level $\underline{\hat{\Pi}}$ and there is sufficient differentiation ( $f t$ is large enough) the regulator will impose a negative fee $s$. Conversely, if the minimum profit level to be achieved is above $\underline{\underline{\Pi}}$, the regulator who is able to choose both prices will choose a positive fee s. Intuitively, the regulator has incentives to set prices and fees lower than a monopolist platform so as to internalize crossgroup externalities across the sides. The requirement that the platform must obtain some profit level restricts how low the price and the fee can be. As long as the required minimum profit level is not too high, the regulator can set a negative fee $\mathrm{s}$, but once the required profit level goes above $\underline{\underline{\Pi}}$ a positive fee is required to ensure sufficient profits to the ISP.

We also show in Appendix B that when the regulator is maximizing profits subject to a constraint of zero profits for the ISP, he will choose an above cost price to users and a below cost fee to applications, $s<0<p-c$, for sufficient differentiation $(f t)$.

This pricing pattern is consistent with the typical case in two-sided market models, where it is optimal (both privately and socially) to subsidize the side that brings more value to the platform while making money off the other side. In our model, the stand-alone value that consumers get in the absence of the network, $v$, and $-p$ are perfect substitutes from the point of view of consumers. It is as if $v$ is already a "subsidy" to consumers, making the user side of the market more valuable to the ISP than the content side. As long as there is sufficient product differentiation compared to network effects, the users' side of the market is more valuable as discussed above. ${ }^{24}$ Hence, for sufficient differentiation (compared to cross-group externalities) the regulator raises the price to consumers before the fee to content providers to ensure that the ISP breaks even.

\section{Duopoly Platforms with Multi-homing Content Providers}

We now extend our model to duopoly competition between two platforms with multi-homing content providers. We assume that consumers single-home, i.e., each consumer buys Internet access from one platform only. Content and applications providers, however, are assumed to multi-home, i.e., they sell through both platforms, paying the fees charged by platforms. As in monopoly, we assume that platforms only offer linear subscription prices and content provider fees.

\footnotetext{
${ }^{24}$ The content side of the market may become more valuable to the ISP only when differentiation is low compared to the relation between cross-group network effects $a$ and $b$. This occurs if the second condition in Proposition 2(ii) does not hold (if $f t \leqslant a^{3} / b$ ).
} 


\subsection{Consumers}

There are two platforms ( 1 and 2) located at $x=0$ and $x=1$. We assume that each platform offers the same intrinsic benefit $v$ to consumers. Given an expected number of content providers $n_{c p k}^{e}$ in each platform $k, k \in\{1,2\}$, the marginal consumer, indifferent between buying from platform 1 or 2 , is located at $x_{i}$ that obeys

$$
v+b n_{c p 1}^{e}-t x_{i}-p_{1}=v+b n_{c p 2}^{e}-t\left(1-x_{i}\right)-p_{2} .
$$

Assuming full market coverage, the sales of the two platforms are

$$
n_{c 1}=\frac{1}{2}-\frac{b\left(n_{c p 2}^{e}-n_{c p 1}^{e}\right)-\left(p_{2}-p_{1}\right)}{2 t}
$$

and

$$
n_{c 2}=1-n_{c 1}
$$

\subsection{Content Providers}

Content providers are defined as in the monopoly model above, that is, they are heterogeneous with respect to the fixed costs of setting up shop. The expected number of consumers that are able to reach each content provider is $n_{c k}^{e}$, if the content provider buys access from platform $k$, $k \in\{1,2\}$. The total revenue for each content provider is $a n_{c k}^{e}$.

Platform $k$ collects a fee $s_{k}$ from each content provider to allow access to its users. Thus, a content provider $j$ 's profit from selling through platform $k$ is

$$
\pi_{j k}=a n_{c k}^{e}-s_{k}-f y_{j}
$$

Each content provider with $\pi_{j k} \geqslant 0$ sets up its business, pays platform $k$ for access to its consumers, and makes non-negative profits from sales to those consumers. Thus, the marginal content firm which is indifferent between being active and staying out of the market is $n_{c p k}=$ $\left(a n_{c k}^{e}-s_{k}\right) / f$ with $k \in\{1,2\} .{ }^{25}$ Since consumers single-home, content providers can only reach the consumers of each platform by buying access from that platform. Essentially, as Armstrong (2006) points out, a "competitive bottleneck" arises as there is no competition for content providers since they make a decision to join one platform independently of the decision to join the other. This phenomenon is common in, for example, competing mobile telecommunications networks (receivers join one network but callers may call all networks) and newspapers (a consumer may subscribe to only one newspaper but advertisers may advertise in all newspapers).

\footnotetext{
${ }^{25}$ This implies that, for example if $n_{c p 1}<n_{c p 2}$, there are some content providers that connect to both ISPs, some that only connect to ISP2 and some that do not connect at all.
} 


\subsection{Demand}

As in the monopoly setup, we look for a fulfilled expectations equilibrium. Each side's expectations are fulfilled and therefore $n_{c k}^{e}=n_{c k}$ and $n_{c p k}^{e}=n_{c p k}, k \in\{1,2\}$. Solving the four equation system given by (24), (25) and $n_{c p k}=\left(a n_{c k}^{e}-s_{k}\right) / f$, the number of consumers and active content providers is

$$
\begin{gathered}
n_{c 1}=\frac{1}{2}+\frac{b\left(s_{2}-s_{1}\right)+f\left(p_{2}-p_{1}\right)}{2(f t-a b)}, \\
n_{c 2}=\frac{1}{2}-\frac{b\left(s_{2}-s_{1}\right)+f\left(p_{2}-p_{1}\right)}{2(f t-a b)}, \\
n_{c p 1}=\frac{a\left(b\left(s_{1}+s_{2}\right)+f\left(t+p_{2}-p_{1}\right)\right)-\left(a^{2} b+2 f t s_{1}\right)}{2 f(f t-a b)},
\end{gathered}
$$

and

$$
n_{c p 2}=\frac{a\left(b\left(s_{1}+s_{2}\right)+f\left(t+p_{1}-p_{2}\right)\right)-\left(a^{2} b+2 f t s_{2}\right)}{2 f(f t-a b)} .
$$

We first consider the unrestricted duopoly equilibrium, then the duopoly equilibrium under network neutrality regulation and finally we study the welfare implications of imposing network neutrality regulation.

\subsection{Unrestricted Duopoly Equilibrium}

When the duopoly platforms are free to set prices to both consumers and content providers, platform k maximizes $\Pi_{k}\left(p_{1}, p_{2}, s_{1}, s_{2}\right)=\left(p_{k}-c\right) n_{c k}+s_{k} n_{c p k}$, with $k \in\{1,2\}$ resulting in equilibrium prices $p_{1}^{D}=p_{2}^{D}=t+c-\left(a^{2}+3 a b\right) / 4 f$ and $s_{1}^{D}=s_{2}^{D}=(a-b) / 4 .{ }^{26}$ The duopolists split the market on the consumer side and profits are $\Pi_{1}^{D}=\Pi_{2}^{D}=\left(4 f t-(a+b)^{2}+4(f t-a b)\right) / 16 f$.

\subsection{Duopoly under Network Neutrality Regulation}

Under network neutrality regulation $s_{1}=s_{2}=0$, and the duopolists independently set their prices to consumers to maximize $\Pi_{1}=\left(p_{1}-c\right) n_{c 1}$ and $\Pi_{2}=\left(p_{2}-c\right) n_{c 2}$ with respect to $p_{1}$ and $p_{2}$, respectively, resulting in equilibrium prices of $p_{1}^{D N N}=p_{2}^{D N N}=t+c-a b / f .{ }^{27}$ The duopolists split the market equally on the consumer side and profits are $\Pi_{1}^{D N N}=\Pi_{2}^{D N N}=$ $(1 / 2)(t-a b / f)$.

\footnotetext{
${ }^{26}$ The second-order conditions are $-f /(f t-a b)<0,-\frac{(2 f t-a b)}{f(f t-a b)}<0$ and $\frac{\left(4 f t-(a+b)^{2}\right)+4(f t-a b)}{4(a b-f t)^{2}}>0$. They are satisfied under Assumption 1. For $n_{c p k}<1$, we need $a+b<4 f$.

${ }^{27}$ The second-order condition, $-f /(f t-a b)<0$, is satisfied under Assumption 1. For $n_{c p k}<1$, we require $a<2 f$.
} 


\subsection{Welfare Implications of Imposing Network Neutrality in Duopoly}

In this section, we proceed as in monopoly by making a point-to-point comparison between unconstrained duopoly and the market equilibrium under network neutrality. As in the monopoly model, we compare changes in price to consumers and fees to content providers when moving from a regime with network neutrality to a regime of no regulation. We obtain the following proposition.

Proposition 3. Comparing unconstrained duopoly with duopoly under network neutrality, we find that, for $a / b>1:$ (i) total surplus is higher in network neutrality; and (ii), the content sector and the platforms have higher profits, but consumers are worse off under network neutrality.

Proof. See Appendix A.2.

Thus, under no regulation, competition for consumers is more intense since profits from content providers can be competed away. As a result, consumers enjoy lower prices and are better off under no regulation than under network neutrality. Network neutrality regulation relaxes price competition, leading to higher profits for platforms. Platforms are better off under network neutrality, which is the opposite to the case in the monopoly model. ${ }^{28}$

An important note is that we assume full market coverage on the consumer side, which implies that price reductions to consumers will only lead to surplus transfers between consumers and platforms. In contrast, on the content provider side, fee increases lead to reductions in the surplus.

We now briefly consider a version of the model where the market on the consumer side is not covered. Let the platforms locate at a distance $d<1 / 2$ each from the endpoints such that ISP 1 locates at $\mathrm{d}$ and ISP 2 locates at $1-d$. We assume that $d$ and $t$ are sufficiently large so that the market is never covered and the platforms compete for consumers located between them. Hence, there will be three marginal consumers denoted $x_{1}, x_{2}$ and $x_{3}$. The consumer located at $x_{1}$ is indifferent between buying from platform 1 and staying out of the market. The consumer located at $x_{2}$ is indifferent between the two platforms and the consumer located at $x_{3}$ is indifferent between staying out of the market and buying from platform 2. Given our utility specification, the locations of these indifferent consumers are given by

$$
\begin{gathered}
x_{1}=d-\frac{v+b n_{c p 1}^{e}-p_{1}}{t}, \\
x_{2}=\frac{1}{2}-\frac{b\left(n_{c p 2}^{e}-n_{c p 1}^{e}\right)-\left(p_{2}-p_{1}\right)}{2 t},
\end{gathered}
$$

\footnotetext{
${ }^{28}$ Note that this runs counter to the observed behavior of ISP: they push for the removal of network neutrality. As we show in Proposition 4, ISPs could benefit from the removal of network neutrality if the market is not fully covered on the consumer side.
} 
and

$$
x_{3}=(1-d)+\frac{v+b n_{c p 2}^{e}-p_{2}}{t} .
$$

Demand on the consumer side is $n_{c 1}=x_{2}-x_{1}$ and $n_{c 2}=x_{3}-x_{2}$. The content provider side remains unchanged. We can then obtain the following proposition.

Proposition 4. Comparing unconstrained duopoly with duopoly under network neutrality when the consumer side is not fully covered, we find that for $a / b>1:$ (i) total surplus either increases or decreases under network neutrality; and (ii) the content sector has higher profits, but the consumers and the platforms are worse off under network neutrality.

Proof. See Appendix A.3.

Proposition 4 shows that the effect on total surplus of imposing network neutrality regulations can now either be positive or negative depending on parameter values even if $a / b>1$. Under no regulation, the competition for consumers is more intense since profits from content providers can be competed away. As a result, consumers enjoy lower prices and are better off under no regulation than under network neutrality. Platforms are also better off under no regulation. This is the opposite result to that of the case when the market was covered due to profits from more consumers entering the market. Content providers have higher profits under network neutrality as was the case with a covered market.

In sum, extending the monopoly model to a duopoly setup, we showed that there still exist parameter ranges for which network neutrality improves total surplus. This echoes earlier theoretical evidence suggesting that introducing competition in a two-sided market does not necessarily lead to a pricing structure that is closer to the socially optimal one (see, for example, Wright (2004), Armstrong (2006) or Hagiu (2007)).

\section{Concluding Remarks}

In this paper, we developed a model of a two-sided market to assess the effects of the Internet departing from "network neutrality" where broadband Internet access providers (telephone and cable TV companies) do not charge a positive fee to content and application providers. We explicitly allowed monopoly and duopoly access providers to charge a positive fee to content and applications providers. Our main point has been that cross-group externalities between consumers and content providers could give a rationale for network neutrality regulations since there exist parameter ranges such that preventing ISPs from charging content providers positive prices for access to consumers increases total surplus. We have showed that one can find such parameter ranges both in the monopoly model and in the duopoly model suggesting that network neutrality regulation could be warranted even when some competition is present in the platform market. However, the overall effect of implementing network neutrality regulations can still be both positive and negative depending on parameter values. 
As noted in the introduction, the economics literature on network neutrality regulation is still in its early stages. Further rigorous economic analysis is needed on issues such as the impact of network neutrality regulation on innovation among content providers, non-linear platform pricing and congestion and broadband penetration. In particular, the issue of price discrimination and two-part tariffs to consumers and content providers is important. Our results rely quite extensively on the platform not being able to appropriate the entire surplus from consumers and content providers. Hence, our results might not be robust to extensive use of price discrimination and two-part tariffs by the platform. We believe, however, that our results will still hold if some surplus is left to consumers and content providers. Nevertheless, our focus has been on the two-sided nature of the market and we believe it to be important for future studies to account for this. A one-sided analysis of two-sided markets may easily lead to incorrect conclusions, as Wright (2004), among others, also have pointed out in other settings.

\section{Appendix}

\section{A Proof of Propositions}

\section{A.1 Proof of Proposition 1}

Starting with network neutrality, consider the impact of removing network neutrality regulation.

Prices and quantities. The difference in equilibrium price to consumers and fee to content providers as we go away from network neutrality to monopolistic two-sided pricing is

$$
\begin{gathered}
\Delta p=p^{M}-p^{N N}=-\frac{(a-b)(a+b)(v-c)}{2\left(4 f t-(a+b)^{2}\right)}<0, \\
\Delta s=s^{M}-s^{N N}=s^{M}=\frac{(a-b) f(v-c)}{4 f t-(a+b)^{2}}>0,
\end{gathered}
$$

while the difference in equilibrium participation levels is

$$
\begin{gathered}
\Delta n_{c}=n_{c}^{M}-n_{c}^{N N}=f(v-c)\left(\frac{2}{4 f t-(a+b)^{2}}-\frac{1}{2(f t-a b)}\right)>0, \\
\Delta n_{c p}=n_{c p}^{M}-n_{c p}^{N N}=(v-c)\left(\frac{a+b}{4 f t-(a+b)^{2}}-\frac{a}{2(f t-a b)}\right) .
\end{gathered}
$$

Equation (37) is negative for $2 f t-a(a+b)>0$, which holds under Assumption 1.

Profits, consumer surplus and content provider surplus. The equilibrium profits of the platform are higher when it is unconstrained:

$$
\Delta \Pi=\Pi^{M}-\Pi^{N N}=f(v-c)^{2}\left(\frac{1}{4 f t-(a+b)^{2}}-\frac{1}{4(f t-a b)}\right)>0 .
$$


Total consumer surplus and content provider profits under private optimum are

$$
C S_{c}^{M}=\frac{2 f^{2} t(v-c)^{2}}{\left(4 f t-(a+b)^{2}\right)^{2}}
$$

and

$$
\Pi_{c p}^{M}=\frac{(a+b)^{2} f(v-c)^{2}}{2\left(4 f t-(a+b)^{2}\right)^{2}} .
$$

Under network neutrality regulation they are

$$
C S_{c}^{N N}=\frac{f^{2} t(v-c)^{2}}{8(f t-a b)^{2}}
$$

and

$$
\Pi_{c p}^{N N}=\frac{a^{2} f(v-c)^{2}}{8(f t-a b)^{2}} .
$$

The change in consumer surplus when network neutrality regulation is removed is then

$$
\Delta C S_{c}=C S_{c}^{M}-C S_{c}^{N N}=\frac{1}{8} f^{2} t(v-c)^{2}\left(\frac{16}{\left(4 f t-(a+b)^{2}\right)^{2}}-\frac{1}{(f t-a b)^{2}}\right)>0
$$

since

$$
\frac{16}{\left(4 f t-(a+b)^{2}\right)^{2}}-\frac{1}{(f t-a b)^{2}}=\frac{(a-b)^{2}\left(4(f t-a b)+\left(4 f t-(a+b)^{2}\right)\right)}{\left(4 f t-(a+b)^{2}\right)^{2}(f t-a b)^{2}}>0
$$

and from Assumption $14 f t-(a+b)^{2}>0$. The change in content provider profits is

$$
\Delta \Pi_{c p}=\Pi_{c p}^{M}-\Pi_{c p}^{N N}=\frac{1}{8} f(v-c)^{2}\left(\frac{4(a+b)^{2}}{\left(4 f t-(a+b)^{2}\right)^{2}}-\frac{a^{2}}{(f t-a b)^{2}}\right) .
$$

It is negative if $2 f t-a(a+b)>0$ which holds under Assumption 1 . To see this, note that

$$
\frac{4(a+b)^{2}}{\left(4 f t-(a+b)^{2}\right)^{2}}-\frac{a^{2}}{(f t-a b)^{2}}=\frac{4(a+b)^{2}(f t-a b)^{2}-a^{2}\left(4 f t-(a+b)^{2}\right)^{2}}{\left(4 f t-(a+b)^{2}\right)^{2}(f t-a b)^{2}} .
$$

The sign is determined by the numerator, which is negative if $2 f t-a(a+b)>0$.

Total surplus. We now calculate the change in total surplus that occurs when network neutrality regulation is removed. Total surplus under the private optimum is

$$
T S^{M}=\frac{f\left(12 f t-(a+b)^{2}\right)(v-c)^{2}}{2\left(4 f t-(a+b)^{2}\right)^{2}}
$$


and under network neutrality regulation

$$
T S^{N N}=\frac{f(v-c)^{2}\left(a^{2}-2 a b+3 f t\right)}{8(f t-a b)^{2}} .
$$

The change in total surplus is then

$$
\Delta T S=T S^{M}-T S^{N N}=\frac{f(v-c)^{2}}{8}\left(\frac{4\left(12 f t-(a+b)^{2}\right)}{\left(4 f t-(a+b)^{2}\right)^{2}}-\frac{\left(a^{2}-2 a b+3 f t\right)}{(f t-a b)^{2}}\right) .
$$

Our objective is to find parameter values such that the removal of network neutrality regulations reduces total surplus i.e., values such that the sign of equation (49) is negative.

By dividing by $f(v-c)^{2}$ and consolidating in one term we get

$$
\frac{\left(12 f t-(a+b)^{2}\right) 8(f t-a b)^{2}-\left(a^{2}-2 a b+3 f t\right)\left(4 f t-(a+b)^{2}\right)^{2}}{8(f t-a b)^{2}\left(4 f t-(a+b)^{2}\right)^{2}} .
$$

The sign of this expression is determined by the numerator. Expanding the numerator and collecting terms in $f t$ we get

$$
(b-a)\left(a^{5}+3 a^{4} b+5 a^{3} b^{2}+5 a^{2} b^{3}+2 a b^{4}-5 a^{3} f t-a^{2} b f t-23 a b^{2} f t-3 b^{3} f t-4 a(f t)^{2}+20 b(f t)^{2}\right)<0,
$$

which can be rewritten as

$$
(a-b)\left(4(f t)^{2}(a-5 b)+f t\left(-5 a^{3}-a^{2} b f t-23 a b^{2}-3 b^{3}\right)-\left(a^{5}+3 a^{4} b+5 a^{3} b^{2}+5 a^{2} b^{3}+2 a b^{4}\right)\right)<0 .
$$

Since we have assumed that $a / b>1$, the sign of the above expression is negative provided that $f t$ is large enough and that $a-5 b$ is negative, that is, if $a / b<5$.

\section{A.2 Proof of Proposition 3}

Starting with network neutrality, consider the impact of removing network neutrality regulation. Since the market is covered in both regimes, consumer participation does not change. The differences in equilibrium prices to consumers and fees to content providers are

$$
\begin{gathered}
\Delta p_{1}=p_{1}^{D}-p_{1}^{D N N}=\Delta p_{2}=p_{2}^{D}-p_{2}^{D N N}=-\frac{a(a-b)}{4 f}<0, \\
\Delta s_{1}=s_{1}^{D}-s_{1}^{D N N}=\Delta s_{2}=s_{2}^{D}-s_{2}^{D N N}=s_{1}^{D}=s_{2}^{D}=\frac{a-b}{4}>0,
\end{gathered}
$$


and the difference in content provider participation is

$$
\Delta n_{c p 1}=n_{c p 1}^{D}-n_{c p 1}^{D N N}=\Delta n_{c p 2}=n_{c p 2}^{D}-n_{c p 2}^{D N N}=-\frac{(a-b)}{4 f}<0 .
$$

The differences in consumer surplus, platform profits and content provider profits are

$$
\begin{gathered}
\Delta C S=C S^{D}-C S^{D N N}=\frac{(a-b)^{2}}{16 f}>0, \\
\Delta \Pi_{1}=\Pi_{1}^{D}-\Pi_{1}^{D N N}=\Delta \Pi_{2}=\Pi_{2}^{D}-\Pi_{2}^{D N N}=-\frac{(a-b)^{2}}{16 f}<0,
\end{gathered}
$$

and

$$
\Delta \Pi_{c p}=\Pi_{c p}^{D}-\Pi_{c p}^{D N N}=-\frac{(a-b)(3 a+b)}{16 f}<0 .
$$

Total welfare is reduced when the network neutrality regulation is removed since

$$
\Delta T S=T S^{D}-T S^{D N N}=-\frac{(a-b)(3 a+b)}{16 f}<0 .
$$

\section{A.3 Proof of Proposition 4}

To prove this Proposition, we first obtain expressions for the number of active consumers and content providers as functions of all four prices. These are

$$
n_{c 1}=\frac{2 a b\left(2 b s_{1}+f\left(2 p_{1}-t+2 d t-2 v\right)\right)+f t\left(b\left(-3 s_{1}+s_{2}\right)+f\left(-3 p_{1}+p_{2}+t-2 d t+2 v\right)\right)}{4 a^{2} b^{2}-6 a b f t+2 f^{2} t^{2}},
$$

$$
n_{c p 1}=\frac{-2 f s_{1} t^{2}+2 a^{2} b\left(2 p_{1}-t+2 d t-2 v\right)+a t\left(b\left(3 s_{1}+s_{2}\right)+f\left(-3 p_{1}+p_{2}+t-2 d t+2 v\right)\right)}{4 a^{2} b^{2}-6 a b f t+2 f^{2} t^{2}},
$$

$$
n_{c 2}=\frac{2 a b\left(2 b s_{2}+f\left(2 p_{2}-t+2 d t-2 v\right)\right)+f t\left(b\left(s_{1}-3 s_{2}\right)+f\left(p_{1}-3 p_{2}+t-2 d t+2 v\right)\right)}{4 a^{2} b^{2}-6 a b f t+2 f^{2} t^{2}}
$$

and

$$
n_{c p 2}=\frac{-2 f s_{2} t^{2}+2 a^{2} b\left(2 p_{2}-t+2 d t-2 v\right)+a t\left(b\left(s_{1}+3 s_{2}\right)+f\left(p_{1}-3 p_{2}+t-2 d t+2 v\right)\right)}{4 a^{2} b^{2}-6 a b f t+2 f^{2} t^{2}} .
$$


The consumer surplus is

$$
\begin{aligned}
& C S=\int_{x_{1}}^{d}\left(v+b n_{c p 1}-t(d-x)-p_{1}\right) d x+\int_{d}^{x_{2}}\left(v+b n_{c p 1}-t(x-d)-p_{1}\right) d x \\
& +\int_{x_{2}}^{(1-d)}\left(v+b n_{c p 2}-t((1-d)-x)-p_{2}\right) d x+\int_{(1-d)}^{x_{3}}\left(v+b n_{c p 2}-t(x-(1-d))-p_{2}\right) d x
\end{aligned}
$$

and the content provider profits are

$$
\Pi_{c p}=\int_{0}^{n_{c p 1}}\left(a n_{c 1}-s_{1}-f y\right) d y+\int_{0}^{n_{c p 2}}\left(a n_{c 2}-s_{2}-f y\right) d y .
$$

Total surplus is defined as the sum of consumer surplus, platform profits and content provider profits.

We first solve for equilibrium prices and fees in the unrestricted duopoly equilibrium. Platform $k$ choose prices and fees to maximize

$$
\Pi_{k}\left(p_{1}, p_{2}, s_{1}, s_{2}\right)=\left(p_{k}-c\right) n_{c k}\left(p_{1}, p_{2}, s_{1}, s_{2}\right)+s_{k} n_{c p k}\left(p_{1}, p_{2}, s_{1}, s_{2}\right)
$$

resulting in symmetric equilibrium prices of

$$
\begin{gathered}
a b\left(8 b^{2} c+f t(-22 c-9 t+18 d t-18 v)\right)+ \\
4 a^{3} b(t-2 d t+2 v)+a^{2}(3 f t(-t+2 d t-2 v)+ \\
\left.4 b^{2}(2 c+t-2 d t+2 v)\right) \\
+2 f t\left(-3 b^{2} c+2 f t(3 c+t-2 d t+2 v)\right) \\
p_{1}^{D}=p_{2}^{D}=\frac{+20 b^{2} t^{2}}{8 a b(a+b)^{2}-2\left(3 a^{2}+20 a b+3 b^{2}\right) f t+20 t^{2}} \\
s_{1}^{D}=s_{2}^{D}=\frac{(a-b) f(4 a b-3 f t)(2 c+(2 d-1) t-2 v)}{8 a b(a+b)^{2}-2\left(3 a^{2}+20 a b+3 b^{2}\right) f t+20 f^{2} t^{2}} .
\end{gathered}
$$

Under network neutrality regulation $\left(s_{1}=s_{2}=0\right)$, equilibrium subscription prices are obtained by each platform setting the price to maximize

$$
\Pi_{k}\left(p_{1}, p_{2}, 0,0\right)=\left(p_{k}-c\right) n_{c k}\left(p_{1}, p_{2}, 0,0\right)
$$

resulting in symmetric subscription prices of

$$
p_{1}^{D N N}=p_{2}^{D N N}=\frac{f t(-3 c-t+2 d t-2 v)+2 a b(2 c+t-2 d t+2 v)}{8 a b-5 f t} .
$$

The second-order conditions are $f\left((a b-f t)^{-1}+2(2 a b-f t)^{-1}\right)<0,(t(3 a b-2 f t)) /((a b-f t)(2 a b-f t))$ 0 , and $(3 f t-4 a b)\left(4 a b(a+b)^{2}-3\left(a^{2}+6 a b+b^{2}\right) f t+8 f^{2} t^{2}\right) /\left(4(a b-f t)^{2}(f t-2 a b)^{2}\right)>0$. 
To satisfy the second-order conditions, we need to impose $f t-2 a b>0$ and $4 a b(a+b)^{2}-$ $3\left(a^{2}+6 a b+b^{2}\right) f t+8 f^{2} t^{2}>0$, that is, that the heterogeneity parameters are sufficiently large.

We now compare the unconstrained duopoly and the market equilibrium under network neutrality. The differences in equilibrium prices to consumers and to content providers are

$$
\begin{gathered}
\Delta p_{1}=p_{1}^{D}-p_{1}^{D N N}=\Delta p_{2}=p_{2}^{D}-p_{2}^{D N N}<0 \\
\Delta s_{1}=s_{1}^{D}-s_{1}^{D N N}=\Delta s_{2}=s_{2}^{D}-s_{2}^{D N N}>0
\end{gathered}
$$

The differences in consumer and content provider participation are

$$
\begin{gathered}
\Delta n_{c 1}=n_{c 1}^{D}-n_{c 1}^{D N N}=\Delta n_{c 2}=n_{c 2}^{D}-n_{c 2}^{D N N}>0, \\
\Delta n_{c p 1}=n_{c p 1}^{D}-n_{c p 1}^{D N N}=\Delta n_{c p 2}=n_{c p 2}^{D}-n_{c p 2}^{D N N}<0 .
\end{gathered}
$$

The differences in consumer surplus, platform profits and content provider profits are

$$
\begin{gathered}
\Delta C S=C S^{D}-C S^{D N N}>0, \\
\Delta \Pi_{1}=\Pi_{1}^{D}-\Pi_{1}^{D N N}=\Delta \Pi_{2}=\Pi_{2}^{D}-\Pi_{2}^{D N N}>0, \\
\Delta \Pi_{c p}=\Pi_{c p}^{D}-\Pi_{c p}^{D N N}<0 . \\
\Delta T S=T S^{D}-T S^{D N N}<0 .
\end{gathered}
$$

Total welfare is reduced when network neutrality regulation is removed if $3 a-23 b<0$ and differentiation parameters $f$ and $t$ are sufficiently large so that $8 a^{2} b\left(3 a^{4}+18 a^{3} b+18 a^{2} b^{2}+\right.$ $\left.54 a b^{3}+11 b^{4}\right) f t+\left(39 a^{3}-31 a^{2} b+491 a b^{2}+21 b^{3}\right) f^{3} t^{3}+5(3 a-23 b) f^{4} t^{4}<16 a^{3} b^{2}(a+b)^{2}\left(a^{2}+\right.$ $\left.a b+2 b^{2}\right)+a\left(9 a^{4}+133 a^{3} b+48 a^{2} b^{2}+730 a b^{3}+76 b^{4}\right) f^{2} t^{2}$.

\section{B Second Best Outcome in the Monopoly Model}

In this appendix, we discuss the second best outcome, when the regulator of the ISP monopolist chooses $p$ and $s$ to maximize total surplus subject to the constraint that the platform's profits are some positive amount $\underline{\Pi}$ :

$$
T S(p, s) \text { s.t. } \Pi(p, s)=\underline{\Pi}
$$


Our objective is to discuss under what conditions we could expect the fee to content providers to be negative in this case.

We set up the Lagrangian as follows:

$$
L=T S(p, s)+\lambda(\Pi(p, s)-\underline{\Pi})
$$

Given concavity of $T S(p, s)$ and $\Pi(p, s)$ in $p$ and $s, L$ is concave in $p$ and $s$ for non-negative $\lambda .^{29}$ The maximization conditions for $p$ and $s$ are

$$
\frac{\partial L}{\partial p}=\frac{\begin{array}{c}
a^{2}(b(1+\lambda) s+f(p-v))+f t(c f(1+\lambda)-f p-2 f \lambda p-b \lambda s+f \lambda v) \\
+a\left(b^{2}(1+\lambda) s-f \lambda s t-b f(1+\lambda)(c-2 p+v)\right)
\end{array}}{(f t-a b)^{2}}=0,
$$

and

$$
\begin{aligned}
& t\left(b^{2} s-f(1+2 \lambda) s t+b f(c+c \lambda-\lambda p-v)\right)+a^{2} b(1+\lambda)(p-v) \\
& \frac{\partial L}{\partial s}=\frac{+a\left(-b^{2}(1+\lambda)(c-p)+2 b(1+\lambda) s t+f \lambda t(-p+v)\right)}{(f t-a b)^{2}}=0 .
\end{aligned}
$$

Solving the system of these two equations, we can obtain explicit expressions of price to users and fee to applications as functions of the Lagrange multiplier $\lambda$ :

$$
p(\lambda)=\frac{c(1+\lambda)(b(a+b)(1+\lambda)-f(1+2 \lambda) t)+\left(a(a+b)(1+\lambda)^{2}-f \lambda(1+2 \lambda) t\right) v}{(a+b)^{2}(1+\lambda)^{2}-f(1+2 \lambda)^{2} t}
$$

and

$$
s(\lambda)=\frac{-f(1+\lambda)(b-\lambda(a-b))(v-c)}{f t(1+2 \lambda)^{2}-(a+b)^{2}(1+\lambda)^{2}} .
$$

We also note that the price cost margin to consumers is

$$
p(\lambda)-c=\frac{\left(f t \lambda(1+2 \lambda)-a(a+b)(1+\lambda)^{2}\right)(v-c)}{f t(1+2 \lambda)^{2}-(a+b)^{2}(1+\lambda)^{2}} .
$$

Substituting in the profit function, we have profits as a function of $\lambda$

$$
\Pi(\lambda)=\frac{f(1+\lambda)\left(-(a+b)^{2}(1+\lambda)^{3}+f \lambda(1+2 \lambda)^{2} t\right)(v-c)^{2}}{\left((a+b)^{2}(1+\lambda)^{2}-f(1+2 \lambda)^{2} t\right)^{2}}
$$

\footnotetext{
${ }^{29}$ In section 2.6, we showed that $T \mathrm{~S}(p, s)$ is concave under Assumption 1 and in section 2.4 we showed that $\pi(p, s)$ is concave under Assumption 1.
} 
Profits are increasing in $\lambda$ for $f t>(a+b)^{2}$ :

$$
\frac{\partial \Pi(\lambda)}{\partial \lambda}=\frac{f^{2}(1+2 \lambda) t\left(3(a+b)^{2}(1+\lambda)^{2}+f(1+2 \lambda)^{2} t\right)(v-c)^{2}}{\left(f t(1+2 \lambda)^{2}-(a+b)^{2}(1+\lambda)^{2}\right)^{3}}>0 .
$$

When the profit constraint is not binding, i.e., when $\lambda=0$, it is socially optimal to charge a negative fee to the content side: $s(0)=-b f(v-c) /\left(f t-(a+b)^{2}\right)<0$ provided that $f t>$ $(a+b)^{2}$, which holds under Assumption 1. It is also optimal to charge a price below marginal cost to consumers.

As we increase $\lambda$ away from zero, the constraint starts binding, and the profits accrued to the ISP increase. The numerator of $s(\lambda)$ is negative if and only if $\lambda<\frac{b}{a-b}$ for $a>b$ The denominator is positive as long as $f t>(a+b)^{2}$, which holds under Assumption 1 , and $\lambda \geqslant 0$ Hence, it follows that given $f t>(a+b)^{2}$ and $a>b, s(\lambda)$ is negative for $0 \leqslant \lambda<\frac{b}{a-b}$ and positive for larger $\lambda, \lambda>\frac{b}{a-b}$. Since ISP profits are increasing in $\lambda$, we have shown that the planner's constrained maximization problem results in a negative fee $s$ when there is sufficient differentiation and profits to be realized are $\underline{\Pi}<\underline{\hat{\Pi}}=\Pi\left(\frac{b}{a-b}\right)>0 .{ }^{30}$

When the regulator maximizes total surplus subject to a zero profit constraint of the ISP, we can show that he or she will choose an above cost price for the users and a below cost fee for the content providers. To see this, consider $\Pi(\lambda)$ for $\lambda$ in $\left(0, \frac{b}{a-b}\right)$ and notice that $\Pi(0)<0,{ }^{31}$ $\Pi\left(\frac{b}{a-b}\right)>0$, and $\Pi(\lambda)$ is continuous in $\lambda .{ }^{32}$ Therefore there exist a $\lambda^{*}$ in $\left(0, \frac{b}{a-b}\right)$ so that $\Pi\left(\lambda^{*}\right)=0$. But for all in $\left(0, \frac{b}{a-b}\right)$ it holds that $s(\lambda)<0$. It follows that the regulator will choose a negative fee to content providers to achieve a zero profit for the ISP. Since the achieved profit is zero while fee $s$ is negative, the regulator must impose an above cost price to users. ${ }^{33}$. In summary, to maximize total surplus while requiring zero profits for the ISP, the regulator will choose an above cost price to users and a below cost fee to applications, $s<0<p-c$, if $f t$ is sufficiently large.

Naturally, for the planner to implement the socially optimal price balance he or she would be required to have detailed information about the state of the world. Network neutrality regulation (setting $s=0$ ) is a much simpler form of regulation which does not require extensive information on the state of the world.

\footnotetext{
${ }^{30}$ From equation (86), we obtain $\Pi\left(\frac{b}{a-b}\right)=\frac{a f\left(b f t-a^{3}\right)(v-c)^{2}}{(a+b)^{2}\left(a^{2}-f t\right)^{2}}>0$ if $f t>a^{3} / b$.

${ }^{31}$ Platform profits are negative if the constraint is not binding: $\Pi(0)=-\frac{(a+b)^{2} f(v-c)^{2}}{\left(f t-(a+b)^{2}\right)^{2}}<0$.

${ }^{32}$ For the denominator of $\Pi(\lambda)$ not to be zero it is sufficient to have $(1+2 \lambda)^{2}>(1+\lambda)^{2}$ which is true for all positive $\lambda$.

${ }^{33}$ It is also easy to show explicitly that $p\left(\lambda^{*}\right)-c>0$ Indeed the price to cost margin for consumers is negative at $\lambda=0$ and positive at $\lambda=b /(a-b)$. We have $p\left(\frac{b}{a-b}\right)-c=\frac{\left(b \mathrm{ft}-a^{3}\right)(v-c)}{(a+b)\left(f \mathrm{t}-a^{2}\right)}>0$ for $f t>a^{3} / b$ and $f t>a^{2}$, where the former was assumed for $\Pi\left(\frac{b}{a-b}\right)>0$ and the latter follows from $f t>(a+b)^{2}$.
} 


\section{References}

Amelio, A. and B. Jullien, 2007, Tying and Freebies in Two-sided Markets. Mimeo available at http://idei.fr/doc/wp/2007/tying.pdf.

Armstrong, M., 2006, Competition in Two-Sided Markets. RAND Journal of Economics 37 , 668-691.

Caillaud, B. and B. Jullien, 2003, Chicken \& Egg: Competition Among Intermediation Service Providers. RAND Journal of Economics 24, 309-328.

Cerf, V. G., 2006a, Prepared Statement of Vinton G. Cerf, U.S. Senate Committee on Commerce, Science, and Transportation. Hearing on "Network Neutrality," February 7, 2006.

Cerf, V. G., 2006b, Prepared Statement of Vinton G. Cerf, U.S. Senate Committee on the Judiciary. Hearing on Reconsidering our Communications Laws, June 14, 2006.

Chen, M. K. and B. Nalebuff, 2007, One-Way Essential Complements. Mimeo. Yale University (April).

Chen, Y. and S. J. Savage, 2011, The Effects of Competition on the Price for Cable Modem Internet Access. The Review of Economics and Statistics 93, 201-217

Cheng, H. K., S. Bandyopadhyay and H. Guo, 2011, The Debate on Net Neutrality: A Policy Perspective. Information Systems Research 22, 60-82.

Choi, J. P. and B. C. Kim, 2010, Net Neutrality and Investment Incentives, RAND Journal of Economics 41, 446-471.

Economides, N., 2005, The Economics of the Internet Backbone. Ingo Vogelsang (ed.) Handbook of Telecommunications. Amsterdam: Elsevier Publishers. Available at http:// www.stern.nyu.edu/networks/Economides_ECONOMICS_OF_THE_INTERNET_BACKBONE. pdf

Economides, N., 2007, The Economics of the Internet. The New Palgrave Dictionary of Economics, London: Macmillan. Available at http://www.stern.nyu.edu/networks/ Economides_Economics_of_the_Internet_for_Palgrave.pdf

Economides, N., 2008, 'Net Neutrality,' Non-Discrimination and Digital Distribution of Content Through the Internet. I/S: A Journal of Law and Policy for the Information Society 4, 209-233. Available at http: //www.stern.nyu.edu/networks/Economides_Net_ Neutrality.pdf.

Economides, N. and B. Hermalin, 2010, The Economics of Network Neutrality. NET Institute Working Paper \#10-25. Available at http: //www.stern.nyu.edu/networks/ Economides-Hermalin_Economics_of_Network_Neutrality.pdf.

Hagiu, A., 2009, Two-Sided Platforms: Product Variety and Pricing Structures. Journal of Economics \& Management Strategy 18, 1011-1043.

Hagiu, A., 2007, Proprietary vs. Open Two-Sided Platforms and Social Efficiency. HBS Working Paper 07-095.

Hermalin, B. and M. L. Katz, 2007, The Economics of Product-Line Restrictions with an ap- 
plication to the Network Neutrality Debate. Information Economics and Policy 19, 215248.

Hogendorn, C., 2007, Broadband Internet: net neutrality versus open access. International Economics and Economic Policy 4, 185-208.

Jamison, M. and J. Hauge, 2008, Getting What You Pay For: Analyzing the Net Neutrality Debate. Mimeo.

Krämer, J. and L. Wiewiorra, 2010, Network Neutrality and Congestion-Sensitive Content Providers: Implications for Service Innovation, Broadband Investment and Regulation. Working Paper, Karlsruhe Institute of Technology.

Musacchio, J., G. Schwartz and J. Walrand, 2009, A Two-Sided Market Analysis of Provider Investment Incentives with an Application to the Net-Neutrality Issue. Review of Network Economics 8, 22-39.

Nocke, V., M. Peitz and K. Stahl, 2007, Platform Ownership. Journal of the European Economic Association 5, 1130-1160.

Peha, J. M., 2006, The Benefits and Risks of Mandating Network Neutrality, and the Quest for a Balanced Policy. Mimeo.

Rochet, J. and J.Tirole, 2003, Platform competition in two-sided markets. Journal of the European Economic Association 1, 990-1029.

Rochet, J. and J. Tirole, 2006, Two-Sided Markets: A Progress Report. RAND Journal of Economics 37, 645-667.

Saltzer, J. H. , Reed, D. P. , and Clark D. D., 1984, End-to-end Arguments in System Design. ACM Transactions on Computer Systems 2, 277-288.

Schuett, F, 2010, Network Neutrality: A Survey of the Economic Literature. Review of Network Economics 9. Article 1.

Weyl, G., 2010, A Price Theory of Multi-sided Platforms. American Economic Review 100, pp 1642-1672

Wright, J., 2004, One-Sided Logic in Two-Sided Markets. Review of Network Economics 3, 44-64. 